\title{
Effects of donor cause of death, ischemia time, inotrope exposure, troponin values, cardiopulmonary resuscitation, electrocardiographic and echocardiographic data on recipient outcomes: A review of the literature
}

\author{
Michael A. McCulloch ${ }^{1}$ (D) | Warren A. Zuckerman ${ }^{2}$ (D) | Thomas Möller ${ }^{3}$ (D) | \\ Kenneth Knecht ${ }^{4}$ (D) | Kimberly Y. Lin ${ }^{5}$ (D) | Gary S. Beasley ${ }^{6}$ (D) | David M. Peng ${ }^{7}$ (D) | \\ Dimpna C. Albert ${ }^{8}$ (D) | Oliver Miera ${ }^{9}$ (D) | Anne I. Dipchand ${ }^{10}$ (D) | Richard Kirk ${ }^{11}$ (D) | \\ Ryan R. Davies ${ }^{12}$
}

${ }^{1}$ University of Virginia Children's Hospital, Charlottesville, VA, USA

${ }^{2}$ Columbia University Medical Center, Morgan Stanley Children's Hospital of New York, New York, NY, USA

${ }^{3}$ Oslo University Hospital Rikshospitalet, Oslo, Norway

${ }^{4}$ Arkansas Children's Hospital, Little Rock, AR, USA

${ }^{5}$ The Children's Hospital of Philadelphia, Philadelphia, PA, USA

${ }^{6}$ Le Bonheur Children's Hospital, Memphis, TN, USA

${ }^{7}$ University of Michigan, Ann Arbor, Michigan

${ }^{8}$ King Faisal Specialist Hospital \& Research Center, Riyadh, Saudi Arabia

${ }^{9}$ Department of Congenital Heart Disease/Pediatric Cardiology, Deutsches Herzzentrum, Berlin, Germany

${ }^{10}$ Labatt Family Heart Centre, Hospital for Sick Children, University of Toronto, Toronto, ON, Canada

${ }^{11}$ Division of Pediatric Cardiology, Children's Medical Center, University of Texas Southwestern Medical Center, Dallas, TX, USA

${ }^{12}$ Department of Cardiovascular and Thoracic Surgery, Children's Medical Center, University of Texas Southwestern Medical Center, Dallas, TX, USA

\begin{abstract}
Background: Heart transplantation has become standard of care for pediatric patients with either end-stage heart failure or inoperable congenital heart defects. Despite increasing surgical complexity and overall volume, however, annual transplant rates remain largely unchanged. Data demonstrating pediatric donor heart refusal rates of $50 \%$ suggest optimizing donor utilization is critical. This review evaluated the impact of donor characteristics surrounding the time of death on pediatric heart transplant recipient outcomes.

Methods: An extensive literature review was performed to identify articles focused on donor characteristics surrounding the time of death and their impact on pediatric heart transplant recipient outcomes.

Results: Potential pediatric heart transplant recipient institutions commonly receive data from seven different donor death-related categories with which to determine organ acceptance: cause of death, need for CPR, serum troponin, inotrope exposure, projected donor ischemia time, electrocardiographic, and echocardiographic results. Although DITs up to 8 hours have been reported with comparable recipient outcomes, most data support minimizing this period to $<4$ hours. CVA as a cause of death may be associated with decreased recipient survival but is rare in the pediatric population. Otherwise, however, in the setting of an acceptable donor heart with a normal echocardiogram, none of the other data categories surrounding donor death negatively impact pediatric heart transplant recipient survival.

Conclusions: Echocardiographic evaluation is the most important donor clinical information following declaration of brain death provided to potential recipient
\end{abstract}

Abbreviations: BNP, brain natriuretic peptide; CHD, congenital heart disease; CK-MB, creatine kinase-myocardial band; CPR, cardiopulmonary resuscitation; CVA, cerebrovascular accident; DIT, donor ischemic time; ECG, electrocardiogram; HCV, hepatitis C virus; HIV, human immunodeficiency virus; LVEF, left ventricular ejection fraction; LVH, left ventricular hypertrophy; OCS, Organ Care Systems; OPTN, Organ Procurement and Transplantation Network; PHTS, Pediatric Heart Transplant Society; SIDS, sudden infant death syndrome; UNOS, United Network of Organ Sharing; VAD, ventricular assist device. 
Correspondence

Michael A. McCulloch, University of

Virginia Children's Hospital, Division of

Pediatric Cardiology, PO BOX 800386 ,

Charlottesville, VA 22908.

Email: mcculloch@virginia.edu institutions. Considering its relative importance, every effort should be made to allow direct image visualization.

KEYWORDS

donor characteristics, heart transplantation, pediatric, recipient outcomes

\section{1 | INTRODUCTION}

Orthotopic heart transplantation has become standard of care for the pediatric population with either end-stage heart failure or inoperable congenital heart defects, in part due to median post-transplant survival of $>15$ years. ${ }^{1}$ Although VADs have improved recipient candidacy and utilization of $\mathrm{ABO}$-incompatible donors have allowed for shorter wait times in younger infants, approximately $20 \%$ of all potential pediatric recipients die or are removed from the waitlist prior to transplantation. ${ }^{2,3}$

Pediatric cardiac surgical volume has increased markedly over the past decade ${ }^{4}$ while pediatric heart transplantation rates have largely plateaued between 500 and 600 annually. ${ }^{5}$ While some of this discrepancy is due to post-surgical survival rates approaching $97 \%,{ }^{4}$ a likely larger component is the nearly $50 \%$ discard rate of available pediatric donor hearts. ${ }^{6}$ Optimizing donor organ management and subsequent organ utilization requires increased attention.

A better understanding of donor characteristic significance is critical to improve organ utilization, minimize waitlist time and mortality, and optimize post-transplant survival. The objective of this manuscript is to determine the relative impact of the following donor characteristics on recipient survival: cause of death, troponin and other cardiovascular biomarkers, ischemia/travel time, inotropic therapy, need for and duration of CPR, ECG findings, and echocardiographic findings.

\section{2 | METHODS}

This review was developed by searching the MEDLINE, Cochrane Library, and Web of Science databases in October 2018 with the help of a medical librarian. Index terms and keywords included heart transplantation, donor selection, tissue and organ procurement, utilization, survival, waitlist, refusal, mortality, morbidity, allocation, ECG, echocardiogram, and pediatric. The search was limited to the English language and year $>2009$. The reference lists of studies selected for inclusion were scanned for relevant articles. A hand search of known articles was also included. After removing duplicates, 1475 articles remained.

\section{3 | DONOR CAUSE OF DEATH}

Cause of death is commonly the first data discussed when considering a potential organ donor. Excluding donation after cardiac death, two major etiology categories arise: non-transferrable and potentially transferrable causes. Non-transferrable causes of death include disease mechanisms leading to irreversible brain damage such as trauma, asphyxia, and CVA while potentially transferrable causes of death are comprised of infectious diseases and malignancy. The relative impact of these two categories on recipient outcomes has received considerable attention in both the pediatric and adult literature.

Pathologic intracranial pressure elevations progressively decrease cerebral perfusion pressure and result in cerebral ischemia. Compensatory responses from the central nervous system result in supra-physiologic surges in catecholamines, sympathetic nervous system output, systemic vascular resistance, and both sodium and water retention in attempts to increase systemic pressures and maintain adequate cerebral perfusion. ${ }^{7}$ Unabated, this response progresses to cerebral ischemia, brainstem herniation, and brain death. During this systemic autonomic 'storm,' the commensurate increases in myocardial preload, afterload, contractility, heart rate, and oxygen demand are similarly profound and can produce significant ventricular dysfunction. ${ }^{8,9}$ Immediately following brainstem herniation, however, there is complete deactivation of the sympathetic nervous system and commonly a significant injury to the ischemia-prone hypothalamic-pituitary axis. This shift suddenly removes all the catecholamine, thyroid hormone, cortisol, vasopressin, and sympathetic nervous system output that were simultaneously straining the myocardium but maintaining end organ perfusion. The resulting physiology is typically characterized by decreased contractility, low systemic vascular resistance, and diabetes insipidus. When such patients become organ donors, they are subsequently managed with a variety of fluid repletion, anti-diuretic hormone, inotropes, vasopressors, and hormone repletion which have the potential to mimic the initial period of brainstem herniation. It is at this point that potential recipient institutions must determine whether such injuries are likely to affect recipient outcomes. Further complicating this decision is the significant up-regulation of inflammatory cytokines accompanying brain death and the theoretical risk of an ischemia/ reperfusion injury, rejection and primary graft dysfunction they may incite immediately following transplantation., 8

Data surrounding organ use from donors with the different types of non-transferrable causes of death are mixed. Several adult studies have demonstrated no association between cause of death and recipient/graft survival ${ }^{11,12}$ but others found CVA to be associated with worse outcomes. ${ }^{13}$ However, the association between CVA and worse outcomes may be related to the increased incidence of hypertension, diabetes mellitus, and tobacco use in donors dying from CVA. ${ }^{11,14}$ The data in pediatric and young adult populations, where CVA is clearly an uncommon cause of death, are similarly mixed. 
Some studies suggest that CVA as the donor cause of death is associated with slightly higher 1-year mortality rates following transplantation, ${ }^{15,16}$ but others have not. ${ }^{17-19}$ While it is plausible that the association between donor CVA and subsequent post-transplant mortality differs between adults and children, there is insufficient data to support this assertion. Unfortunately, there is even less data on other non-transferable causes of donor death. Although anecdotal concerns have been expressed regarding the use of donors dying from either smoke inhalation or drowning, there is inadequate data to specifically address these issues.

Transmission of pathogenic microorganisms from donor to recipient is a constant source of concern for transplant centers. This heightened sense of awareness is further exacerbated by the recipient's impending immunosuppressed status and when a pathogen was the donor's cause of death. However, successful transplantation of non-lymphoid organs such as the heart (as compared to lungs and intestines) have occurred from both pediatric and adult donors infected with influenza, ${ }^{20-22}$ bacterial meningitis, ${ }^{23}$ and bacteremia. ${ }^{24,25}$ The use of such organs, often with anti-microbial therapy in both the donor and recipient, is supported by the American Society of Transplantation Infectious Disease Community of Practice. ${ }^{26}$ Despite these recommendations, however, actual utilization of such 'high-risk donors' is uncommon in the pediatric population, accounting for only $4.1 \%$ of all pediatric transplantations. ${ }^{27}$ Considering the overall $50 \%$ discard rate of potential pediatric donor hearts, it is not surprising that acceptance of HIV- or HCV-positive donor organs is negligible, despite no reported cases of recipient HIV transmission and recent medication regimen effectively eradicating $\mathrm{HCV}$ in adults receiving organs from $\mathrm{HCV}$-infected donors. ${ }^{28}$ Of note, presumably in part due to low transmission rates, approximately $3 / 4$ of respondents in a recent international survey of pediatric heart transplant physicians said they would accept organs from infants exposed to known or suspected HIV- or HCV-infected mothers. ${ }^{29}$

Although far less common, donors with active or prior malignancy history are another potential source for organ donation with disease transmission. The largest study assessing this risk evaluated over 8000 potential Chinese donors across all age ranges with a positive cancer history resulting in over 700 organ transplants. ${ }^{30}$ While there was no increased incidence of cancer transmission, they found significantly worse survival in heart transplant recipients from donors with either hematologic or otorhinolaryngologic cancers but not with central nervous system tumors. A similar lack of tumor transmission was found in a smaller adult study including only three heart transplantations. ${ }^{31}$

The overall paucity of data on this subject prompted the OPTN/ UNOS to establish a Disease Transmission Advisory Committee tasked with producing guidelines on organ acceptance from donors with a positive malignancy history. Their document recommended employing a strategy of utilizing anticipated donor malignancy recurrence-free survival or "cure" rates as a surrogate marker for transmission risk. 'Low risk' would be expected from donors who are cancer free for at least 5 years with a cure probability of >99\%; 'intermediate risk' would be those with a 90\%-99\% cure rate; and 'high risk' would be associated with incurable cancers, insufficient follow-up or cure probability $<90 \% .{ }^{32}$ Additional consideration should be given to the metastatic potential of the donor's current or prior malignancy. In general, however, considering the overall limited data and near absence in the pediatric population, there is insufficient data to make any meaningful recommendations for the pediatric donor with a history of or active malignancy.

Donors with an unrecognized cause of death pose another specific challenge for organ transplantation. Considering the significant electrocardiographic abnormalities associated with the brain death-induced electrolyte and neurohormonal changes, ${ }^{33}$ it may be impossible to definitively exclude a channelopathy in patients with unknown cause of death. A similar concern is the neonatal donor dying from SIDS. However, a small study demonstrated heart transplantation from SIDS donors with normal ejection fraction had outcomes comparable to non-SIDS donors. ${ }^{34}$

\section{4 | DONOR TROPONIN AND OTHER BIOMARKERS}

Serum biomarkers of donor myocardial cell death are commonly elevated immediately after CPR or the catecholamine surge accompanying brainstem herniation. While values such as troponin and CK-MB are theoretically attractive due to their wide availability and myocardial specificity, ${ }^{35}$ it is important to understand their actual utility in potential donor heart selection.

Troponin-I and troponin-T are sensitive and specific to myocardial injury and are routinely obtained in both pediatric and adult donors. However, both isoforms can remain elevated for several days after an injurious event has terminated, ${ }^{35}$ significantly complicating their interpretation. A Eurotransplant database study of 774 adult recipients demonstrated elevated donor troponin values, but not CK-MB values, to be associated with decreased 3-year survival. ${ }^{36}$ By comparison, a single-center adult study of 159 potential heart donors demonstrated higher troponin values to be associated with an increased incidence of segmental wall motion abnormalities and lower ejection fractions but not with 1-year recipient survival. ${ }^{37}$ Considering the average ejection fraction of donor hearts ultimately harvested for transplant was $>60 \%$, these data suggested troponin to be associated with acute myocardial injury but not with potential for recovery or recipient outcomes.

This assertion is widely supported in the adult literature. Two UNOS database studies of approximately 11000 adult donors in which the first assessed all organs with normal ejection fractions and found no association between troponin values and recipient outcomes and a second in which 472 recipients received hearts with a median initial ejection fraction of $35 \%$ but normalized prior to transplant, similarly found no association between troponin values and recipient outcomes. ${ }^{38,39}$ Several other smaller adult studies have demonstrated elevated troponin values to be associated with left ventricular dysfunction on initial echocardiograms but not with recipient survival ${ }^{40,41}$ or primary graft dysfunction. ${ }^{42}$ 
Only two pediatric studies have addressed the association between myocardial injury biomarkers and recipient outcomes. A large, single-center pediatric cohort of 182 heart transplant recipients demonstrated no correlation between final troponin or CK-MB values and recipient outcomes, though all donor echocardiograms exhibited normal function prior to transplant. ${ }^{17}$ An OPTN database study of 657 heart transplant recipient $<21$ years of age similarly demonstrated no association between final donor troponin value and recipient outcomes and instead recommended a practice of determining troponin trends and timing from declaration of brain death. ${ }^{43}$

Several small studies of both pediatric ${ }^{44}$ and adult donors ${ }^{45-47}$ have failed to demonstrate the utility of BNP and NT-proBNP values in predicting recipient outcomes but some have shown weak correlations with early myocardial dysfunction. ${ }^{45,47}$

\section{5 | DONOR ISCHEMIA/TRAVEL TIME}

DIT is defined as the time elapsed between aortic cross-clamp during organ procurement and coronary artery reperfusion during heart implantation. This topic has received a great deal of attention in the pediatric population and was a 2017 ISHLT registry report focus. The most commonly reported mean DIT in pediatric heart transplantation is approximately 3.5 hours; although ranges have extended to 10 hours, DIT > 6 hours remains unusual. ${ }^{48-52}$ In a recent survey describing donor acceptance practices of pediatric heart transplant clinicians, $45 \%$ of respondents said they would accept a donor heart with DIT <4 hours, $22 \%$ up to 5 hours, and another $33 \%$ would accept up to 6 hours DIT. ${ }^{29}$ Several of the larger registry-based studies have noted longer DIT to be related to younger age, ${ }^{48,50,52}$ diagnosis of $\mathrm{CHD},{ }^{48,50,52}$ mechanical circulatory support, ${ }^{52}$ and higher acuity. ${ }^{48,52}$ Longer DIT has also been described outside of North America, though reporting has been variable. $^{52}$

DIT >4 hours has been associated with increased intensive care unit and hospital stay ${ }^{51,52}$ and need for mechanical ventilator support, ${ }^{51}$ but has not been demonstrated to impact rejection or coronary allograft vasculopathy. ${ }^{52}$ In the majority of studies, longer DIT is associated with primary graft failure, ${ }^{15,48,50,52-55}$ but not long-term graft or recipient survival. ${ }^{15,48-50,52,54-56}$ Subgroup analyses have demonstrated conflicting age-related effects of DIT on outcomes, ${ }^{49,50,52,54}$ with some concluding adolescence to be the highest risk period ${ }^{50,54}$ while others found worse outcomes in infants. ${ }^{52}$

DIT is one of the most commonly cited parameters used to determine outcomes in the first year after heart transplant. A large retrospective cohort of pediatric heart transplant recipients $(n=4716)$ spanning over two decades demonstrated significantly improved 1-year survival in those with DIT $<3.5$ hours. $^{48}$ The 2017 ISHLT registry report found DIT $>4$ hours was independently associated with decreased survival at both $1(87 \%$ vs $92 \%)$ and 5 years $(77 \%$ vs $82 \%)$ post-transplant, but the effect was no longer present at 10 or 15 years; there was no long-term effect on morbidity. ${ }^{52}$
It must also be recognized that although DIT is a convenient, objective variable for evaluation, it is comprised of several confounding components. CHD patients following multiple sternotomies commonly require prolonged explant times, producing unforeseen technical challenges. Subsequent survival differences may be attributable to recipient factors rather than issues surrounding donor distance or travel time. Further, while there is an obvious direct relationship between DIT and travel time, they are not identical and the correlation between the two is often poor. One large retrospective adult study of over 14000 transplants demonstrated that when accounting for DIT, transplant center volume, and both recipient and donor characteristics, a $7 \%$ reduction in mortality at 30 days and a $6 \%$ reduction in mortality at 1 year were noted for every 100 -mile increase in donor-recipient distance; there were no distance related-survival differences in unadjusted Kaplan-Meier curves. ${ }^{57}$ Conversely, the authors did find DIT to be an independent predictor for mortality at both 30 days and 1 year, and they hypothesized that after controlling for the detrimental impact of prolonged DIT, there must be a hidden, protective association between recipient survival and longer donor distances, which may be a surrogate for differences in myocardial cooling times or preservation practices. Certainly from the existent data, despite long DIT and travel distances, good outcomes can be achieved in both pediatric and adult recipients. ${ }^{49,57}$

Of note, some data from adult studies suggest that warm ischemic time (or surgical implant time) may have a more important impact on post-transplant outcomes than prolonged cold ischemic time. ${ }^{58}$ However, surgical implant time is highly confounded with measures of recipient risk including a history of prior procedures, the need for concomitant procedures at the time of transplantation, and technical challenges with allograft implantation. No recommendations on what constitutes excessive warm ischemic time can be made, although it is prudent to reduce warm ischemia as much as practical.

A recent review provides biochemical comparisons between common preservation solutions and relevant preservation studies, but there have been no new developments in this area for a considerable time. ${ }^{59}$ Hypothermia alone is unable to abolish all cellular damage as metabolism persists at approximately 5\%-10\% of normal. The OCS is a potential solution, allowing prolonged (up to 8 hours) normothermic myocardial perfusion, but is currently only suitable for older teenagers due to instrumentation size. This technology is expanding potential geographic zones for organ procurement and reducing the detrimental effects of DIT due to unanticipated factors such prolonged explant times. ${ }^{60,61}$

\section{6 | DONOR CARDIOPULMONARY RESUSCITATION}

CPR is relatively common in organ donors, either leading to their brain death or as a result. The challenge this history presents for recipient institutions is the inherent warm ischemic time and its potential short- and long-term effects on recipient outcomes. Due to these theoretical concerns, hearts from CPR-positive donors are routinely 
rejected. ${ }^{14,17,62}$ Considering CPR-positive donors comprise up to $40 \%$ of some pediatric series, ${ }^{17}$ determining the relative importance of this information is paramount to expanding the available donor pool.

A PHTS study examining the effect of donor characteristics on outcomes of 3149 recipients found no donor characteristics, including presence or absence of donor CPR, to have a negative effect on overall recipient outcomes. ${ }^{50}$ Likewise, a 2011 study of pediatric heart transplant recipients using the UNOS database found no effect of donor CPR on recipient survival at 30 days, 1 , and 5 years post-transplant. ${ }^{63}$ A recent systematic review came to similar conclusions, supporting consideration of transplant after donor CPR, citing these and three older studies specifically relevant to pediatric heart transplantation. ${ }^{64}$ Data from several adult studies also support the use of donor hearts without consideration of CPR status. ${ }^{36,65,66}$

Interestingly, a single-institution study from France actually found higher 5- and 10-year survival in their adult heart transplant recipients who received CPR-positive donor hearts, prompting the authors to suggest donor myocardial ischemic preconditioning may have salutary effects. ${ }^{67}$ This has been similarly demonstrated in a pediatric cohort. ${ }^{63}$ It should be noted, however, that many of the studies promoting the use of CPR-positive donors also demonstrate normal LVEF in the entire cohort, ${ }^{17,38,63,67}$ suggesting that echocardiographic measures of cardiac function are a more important factor in recipient outcome than whether or not CPR occurred. ${ }^{16}$ Therefore, in the absence of data suggesting a negative association between donor CPR and recipient outcomes, its history, regardless of duration, should not preclude transplantation of an otherwise acceptable donor heart. ${ }^{50,62-64,67}$

\section{7 | DONOR INOTROPE EXPOSURE}

Following brainstem herniation, the body's neurohormonal response, designed to maintain cerebral perfusion pressure, is suddenly truncated. The result is a loss of sympathetic and adrenergic output producing a catecholamine, afterload, and preload deficient state that must be mitigated if organs are to be preserved for donation. Inotrope infusions and fluid resuscitation comprise the majority of interventions undertaken to maintain adequate organ perfusion, but could theoretically induce permanent donor myocardial injury when used excessively. This concern has led some to define inotrope supported donor hearts as 'marginal ${ }^{168}$ and is a common indication for organ refusal. ${ }^{69}$ Whether donor inotrope exposure actually alters pediatric heart transplant recipient outcomes is therefore of significant interest.

Studies suggesting a negative impact of donor inotropic exposure are rare. An adult study assessing high ( $>10 \mathrm{mcg} / \mathrm{kg} / \mathrm{min}$ ) verses low dose ( $<10 \mathrm{mcg} / \mathrm{kg} / \mathrm{min}$ ) donor dopamine exposure on recipient outcomes found a non-significant trend toward endomyocardial biopsy evidence of myocyte necrosis in the high-dose group but no differences in donor ejection fraction, post-transplant ICU duration or 5-year recipient survival. ${ }^{70}$ A PHTS model predicting 1-year post-transplant survival using recipient or donor factors demonstrated a weak association between lower survival and 'higher donor vasoactive support,' but only in recipients with CHD and only in a model that included both donor and recipient data. ${ }^{18}$ The 2017 ISHLT registry report cited donor inotrope use to be associated with decreased 1-year post-transplant survival in recipients $<1$ year, but without mention of number of inotropes, dosing, or ventricular function. ${ }^{52}$

By comparison, the majority of studies assessing donor inotrope use have either shown no association with post-transplant outcomes $^{50,68,70-73}$ or beneficial effects. ${ }^{39,71,74}$ PHTS data of over 3000 children showed no correlation between donor inotrope exposure on recipient 1-year survival, even when differentiated by high verses low dose or when combined with need for CPR, head trauma as cause of death and prolonged ischemic time; further, donor exposure to hormonal therapy was associated with improved recipient outcomes. ${ }^{50}$ A large single-center study of 192 pediatric recipient/ donor pairs evaluating donor exposure to high dose (>5 mcg/ $\mathrm{kg} / \mathrm{min}$ ), low dose, and no dopamine demonstrated no difference in 1-year survival and a significantly decreased incidence of post-transplant right heart failure when donors received dopamine. ${ }^{71}$ Several adult studies have also demonstrated inotropic support to be associated with either higher ${ }^{74}$ or similar $^{36} 3$-year graft survival and without difference in primary graft failure. ${ }^{72-74}$

A particular challenge is use of donor hearts with previously depressed left ventricular function receiving inotropic support. These characteristics comprise the most common indications for pediatric organ refusal ${ }^{68,69}$ but over the past two decades, acceptance of such organs has increased $30 \%$ without any difference in recipient outcomes. ${ }^{69}$ A large UNOS database study of over 11000 adults demonstrated no difference in primary graft failure rates, 30-day, 1-, 3- or 5-year survival between those who received donor hearts with early dysfunction (average ejection fraction 35\%) requiring inotropic support to achieve normal preimplant function or those with normal function throughout the entire preimplant period. ${ }^{39}$ These data suggest concerns that donor inotropic support can temporarily augment donor systolic function and misrepresent eventual recipient outcomes are unfounded.

One plausible explanation for this lack of association between recipient outcomes and donor inotrope exposure, particularly in hearts initially demonstrating left ventricular dysfunction, is the commensurate component of time after brain death. As with many acute, non-ischemic myocardial insults (ie, myocarditis), time and supportive medical management are commonly adequate to allow complete recovery. This assertion is supported by several adult studies demonstrating longer time from declaration of brain death is associated with improved rates of primary graft failure. ${ }^{39,73}$

\section{DONOR ELECTROCARDIOGRAM}

ECG evaluation of a potential heart donor is nearly universally provided to recipient institutions to allow an assessment of prior or ongoing myocardial ischemia, intrinsic channelopathies, accessory pathways, or pathologic hypertrophy. However, no pediatric and only a few adult studies exist to guide the clinician on donor allograft 
acceptance based on these findings. This process is particularly challenging as ECG changes associated with brain death, the most common indication for organ donation, are well documented to include ST segment depression and elevation, $T$ wave inversion, $U$ waves, QT prolongation, and LVH. ${ }^{13,75,76}$ Considering these changes are attributed to the transient autonomic storm and electrolyte abnormalities that accompany brain death, ${ }^{13,75,76}$ their impact on long-term recipient survival is uncertain.

The largest study to address this issue examined 980 adult donor ECGs, of which 51\% were noted to have one or more abnormalities defined as ectopy/arrhythmia, conduction delay, ventricular hypertrophy, chamber enlargement, pathologic Q waves, ST segment changes, or inverted T waves. ${ }^{75}$ Pathologic Q waves had a high specificity, though low sensitivity, for the detection of reduced LVEF and regional wall motion abnormalities on echocardiogram. Atrial or ventricular ectopy and conduction delays were rare. $\mathrm{LVH}$, considered a relative contraindication to heart transplantation in adult literature ${ }^{77,78}$ due to a perceived risk of primary graft dysfunction, particularly when paired with prolonged DITs, ${ }^{79}$ was present in $8 \% .{ }^{75}$ This was significantly more common in donors who died of cerebrovascular causes as compared to traumatic brain injury or anoxia and was hypothesized to be secondary to myocardial edema. Corrected QT (QTC) was $>480 \mathrm{~ms}$ in $21 \%$ and $>500 \mathrm{~ms}$, in $15 \%$. Although no analyses were performed regarding recipient outcomes, aside from PR and QRS intervals there were no associations between ECG findings and organ utilization.

Another adult study evaluated the association of donor QTC $>500 \mathrm{~ms}$ on 1-year post-transplant recipient outcomes. ${ }^{76}$ At study conclusion, donor QTc prolongation was not associated with recipient survival or persistence of QTc prolongation. Of interest, however, was a significant association between donor QTc prolongation and increased risk of cardiac allograft vasculopathy which was hypothesized to be related to proinflammatory cytokines released at the time of brain death.

Given brain death's transient effect on the myocardium, it is reasonable to repeat an ECG after periods of hemodynamic stability, ${ }^{75}$ particularly when initial studies are significantly abnormal. With the available literature to date, there is little additional guidance offered from the ECG outside of an echocardiogram, as no independent ECG components have proven to be predictive of graft outcomes. ${ }^{13,36,75,76}$ This must, however, be interpreted in the context of a known cause of death. Given that cerebrovascular causes of death result in similar abnormal ECG findings, the donor cause of death needs to be clarified to help rule out intrinsic conduction abnormalities, such as a channelopathy. ${ }^{13}$

\section{9 | DONOR ECHOCARDIOGRAPHIC EVALUATION}

All donor information provided to potential pediatric recipient institutions is intended to allow an estimate of that heart's short and long-term functional longevity. Cause of death and need for CPR describe prior finite events associated with exacerbations of catecholamine, cytokine, and sympathetic nervous system upregulation. Serum biomarkers of myocardial injury measure the immediate quantity of cellular injury associated with these prior events and their downward trend describes the time course of insult cessation. Need for donor inotrope therapy is commonly required to offset the neurohormonal void that develops following brainstem herniation and ECG changes are typically reflective of myocardial strain and electrolyte disarray. Donor ischemia time is a predictable parameter largely determined by donor and recipient locations. Echocardiographic evaluation, however, is arguably the most representative measure of current donor left ventricular function and potentially the most important data available to any potential recipient institution.

Numerous studies have demonstrated decreased utilization of potential donor hearts with echocardiographic evidence of ejection fractions $<50 \%,{ }^{6,17,19,68,69,80}$ and ISHLT guidelines have similarly recommended refusal of donor hearts with ejection fractions $<40 \%{ }^{78}$ This practice has been supported by several pediatric ${ }^{16,17}$ and adult $\mathrm{t}^{81}$ studies suggesting higher rates of graft failure following transplant of hearts with ejection fractions $<50 \%$ and a recent pediatric donor utility survey demonstrating half of all respondents would decline an otherwise acceptable organ with an ejection fraction $<50 \%{ }^{29}$

Conversely, a larger number of pediatric and adult studies have demonstrated comparable recipient outcomes following transplantation of hearts with ejection fractions $<50 \%{ }^{19,36,39,69,82}$ and/or with evidence of segmental wall motion abnormalities. ${ }^{36,82}$ This difference may be secondary to increased time intervals between initial echocardiograms demonstrating poor function (oftentimes shortly after herniation) and preharvest myocardial function, (whether documented by echocardiogram or not) with the time interval allowing for myocardial recovery from the neurologic death-induced "catecholamine storm." ${ }^{8}$ Several pediatric ${ }^{19}$ and adult ${ }^{39,83}$ studies have documented the phenomenon of significantly improved function between initial and final (preharvest) echocardiogram following a combination of time and medical management using inotropic and/ or hormonal therapy. These data support serial echocardiographic evaluation of potential donor hearts to assess for functional changes following the systemic response to brain death.

It is important to note a large number of studies in this document have demonstrated no difference in recipient/graft outcomes following transplantation with donor hearts based on their history of CPR, ${ }^{14,16,17,38,63,67}$ troponin elevations, ${ }^{16,38,43,66,67}$ inotropic infusion exposure, ${ }^{43,70,71}$ ischemia time, ${ }^{14,16,38,43,67}$ or cause of death, $8,11,16,34,66,67,70,84$ have been in the setting of normal ejection fractions. This suggests that donor ejection fraction may be the most important information available to a potential recipient institution, a sentiment mirrored by others. ${ }^{13}$

Lastly, two pediatric studies have demonstrated concerning disparity in image interpretation between the 'local,' donor site cardiologist and central laboratory evaluations of left ventricular function. ${ }^{85,86}$ Considering the relative importance of echocardiographic 
measures of function in the decision to accept or decline a potential heart, it is reasonable for recipient sites to request direct visualization of echocardiographic images.

\section{0 | SUMMARY}

An extensive review of the available international scientific literature as of $\mathbf{2 0 1 8}$ has determined that none of the following donor characteristics are independently associated with recipient outcomes: cause of death (aside possibly from CVA), donor troponin values, history of CPR, use of inotropic support, or ECG information (assuming a known cause of death in the setting of marked QTc prolongation as cannot otherwise rule out a channelopathy). It is important to note that available data do not address the additive effect of multiple variables in the same donor.

Although several studies have demonstrated comparable outcomes following heart transplantation with DITs $>6$ hours, every effort should be made to keep this interval to $<4$ hours.

Seemingly, the single most important donor information provided a potential recipient institution is the echocardiographic measurement of ejection fraction. When normal, virtually all other donor factors become irrelevant. Use of donor hearts with ejection fraction $<50 \%$ and/or with focal segmental wall motion abnormalities is somewhat more controversial. Such organs have comprised no more than $8 \%$ of the total donor pool in any of the adult or pediatric studies and have been transplanted with mixed results. Based on the available data, it is reasonable to consider these marginal organs for transplantation but no strong recommendations can be made.

Combined with adult and pediatric studies showing marked differences in echocardiographic interpretations between local and core laboratories, these data lead to our assertion that every effort should be made to allow direct echocardiographic image evaluation by potential recipient sites.

\section{ACKNOWLEDGMENTS}

The authors would like to thank Elaine Attridge, MLS, from the University of Virginia's Claude Moore Health Sciences Library for her help optimizing the literature search.

\section{AUTHORS' CONTRIBUTION}

MAM, RK, RRD, OM, and AID contributed to the conception and design of the manuscript. MAM, WAZ, TM, KK, KYL, GSB, DMG, and DCA contributed to data acquisition and interpretation as well as drafting of the initial manuscript. All authors contributed to the final manuscript, approve its version and agree to be accountable for all aspects of the work.

\section{ORCID}

Michael A. McCulloch iD https://orcid.org/0000-0003-4837-6819 Warren A. Zuckerman (iD https://orcid.org/0000-0003-3856-7726 Thomas Möller (iD https://orcid.org/0000-0002-1159-3206
Kenneth Knecht iD https://orcid.org/0000-0002-4228-4473

Kimberly Y. Lin (iD https://orcid.org/0000-0003-1582-9797

Gary S. Beasley iD https://orcid.org/0000-0001-6137-6114

David M. Peng (iD https://orcid.org/0000-0001-7763-7518

Dimpna C. Albert (iD https://orcid.org/0000-0002-5101-6905

Oliver Miera iD https://orcid.org/0000-0002-7643-1611

Anne I. Dipchand (ID https://orcid.org/0000-0001-6323-7222

Richard Kirk iD https://orcid.org/0000-0002-2831-7857

Ryan R. Davies (iD https://orcid.org/0000-0003-4631-9685

\section{REFERENCES}

1. Rossano JW, Cherikh WS, Chambers DC, et al. The International Thoracic Organ Transplant Registry of the International Society for Heart and Lung Transplantation: twenty- first pediatric heart transplantation report - 2018; focus theme: multiorgan transplantation. J Heart Lung Transplant. 2018;37(10):1184-1195.

2. Chen S, Dykes JC, McElhinney DB, et al. Haemodynamic profiles of children with end-stage heart failure. Eur Heart $J$. 2017;38(38):2900-2909.

3. Singh TP, Almond CS, Piercey G, Gauvreau K. Trends in wait-list mortality in children listed for heart transplantation in the United States: era effect across racial/ethnic groups. Am J Transplant. 2011;11(12):2692-2699.

4. Jacobs JP, He X, Mayer JE, et al. Mortality trends in pediatric and congenital heart surgery: an analysis of the society of thoracic surgeons congenital heart surgery database. Ann Thorac Surg. 2016;102(4):1345-1352.

5. Dipchand Al, Rossano JW, Edwards LB, et al. The Registry of the International Society for Heart and Lung Transplantation: eighteenth official pediatric heart transplantation report-2015; focus theme: early graft failure. J Heart Lung Transplant. 2015;34(10):1233-1243.

6. Khan AM, Green RS, Lytrivi ID, Sahulee R. Donor predictors of allograft utilization for pediatric heart transplantation. Transpl Int. 2016;29(12):1269-1275

7. Kotloff RM, Blosser S, Fulda GJ, et al. Management of the potential organ donor in the ICU. Crit Care Med. 2015;43(6):1291-1325.

8. Cohen O, La Zerda De DJ, Beygui R, Hekmat D, Laks H. Donor brain death mechanisms and outcomes after heart transplantation. Transplant Proc. 2007;39(10):2964-2969.

9. Pérez López S, Otero Hernández J, Vázquez Moreno N, Escudero Augusto D, Alvarez Menéndez F, Astudillo GA. Brain death effects on catecholamine levels and subsequent cardiac damage assessed in organ donors. J Heart Lung Transplant. 2009;28(8):815-820.

10. Ritschl PV, Ashraf MI, Oberhuber R, et al. Donor brain death leads to differential immune activation in solid organs but does not accelerate ischaemia-reperfusion injury. J Pathol. 2016;239(1):84-96.

11. Singhal AK, Sheng X, Drakos SG, Stehlik J. Impact of donor cause of death on transplant outcomes: UNOS registry analysis. Transplant Proc. 2009;41(9):3539-3544.

12. Ganesh JS, Rogers CA, Banner NR, Bonser RS. Donor cause of death and medium-term survival after heart transplantation: a United Kingdom national study. J Thorac Cardiovasc Surg. 2005;129(5):1153-1159.

13. Dorent R, Gandjbakhch E, Goéminne C, et al. Assessment of potential heart donors: a statement from the French heart transplant community. Arch Cardiovasc Dis. 2018;111(2):126-139.

14. Quader M, Wolfe L, Katlaps G, Kasirajan V. Donor heart utilization following cardiopulmonary arrest and resuscitation: influence of donor characteristics and wait times in transplant regions. J Transplant. 2014;2014(4):1-7.

15. Kirk R, Dipchand Al, Edwards LB, et al. The Registry of the International Society for Heart and Lung Transplantation: fifteenth 
pediatric heart transplantation report-2012. J Heart Lung Transplant. 2012;31(10):1065-1072.

16. Zafar F, Jaquiss RD, Almond CS, et al. Pediatric heart donor assessment tool (PH-DAT): a novel donor risk scoring system to predict 1-year mortality in pediatric heart transplantation. J Heart Lung Transplant. 2018;37(3):332-339.

17. Easterwood R, Singh RK, McFeely ED, et al. Pediatric cardiac transplantation using hearts previously refused for quality: a single center experience. Am J Transplant. 2013;13(6):1484-1490.

18. Schumacher KR, Almond C, Singh TP, et al. Predicting graft loss by 1-year in pediatric heart transplant candidates: an analysis of the PHTS database. Circulation. 131:890-898.

19. Krishnamoorthy $\mathrm{V}$, Borbely $\mathrm{X}$, Rowhani-Rahbar A, Souter MJ, Gibbons E, Vavilala MS. Cardiac dysfunction following brain death in children. Pediatr Crit Care Med. 2015;16(4):e107-e112.

20. Cockbain AJ, Jacob M, Ecuyer C, Hostert L, Ahmad N. Transplantation of solid organs procured from influenza A H1N1 infected donors. Transpl Int. 2011;24(12):e107-e110.

21. Halliday N, Wilmore S, Griffiths PD, Neuberger J, Thorburn D. Risk of transmission of $\mathrm{H} 1 \mathrm{~N} 1$ influenza by solid organ transplantation in the United Kingdom. Transplantation. 2012;93(5):551-554.

22. Smith CJ, McCulloch MA, Shirley D-A, L'Ecuyer TJ. Pediatric heart transplantation from an influenza B-positive donor. Pediatr Transplant. 2019;23(2):e13353-e13354.

23. Bahrami T, Vohra HA, Shaikhrezai K, et al. Intrathoracic organ transplantation from donors with meningitis: a single-center 20year experience. Ann Thorac Surg. 2008;86(5):1554-1556.

24. Mularoni A, Bertani A, Vizzini G, et al. Outcome of transplantation using organs from donors infected or colonized with carbapenem-resistant gram-negative bacteria. Am J Transplant. 2015;15(10):2674-2682.

25. Ison MG, Grossi P, The AST Infectious Diseases Community of Practice. Donor-derived infections in solid organ transplantation. Am J Transplant. 2013;13(s4):22-30.

26. Mehta SR, Logan C, Kotton CN, Kumar D, Aslam S. Use of organs from donors with bloodstream infection, pneumonia, and influenza: results of a survey of infectious diseases practitioners. Transpl Infect Dis. 2017;19(1):e12645-e12648.

27. Sahulee R, Lytrivi ID, Savla JJ, Rossano JW. Centers for Disease Control "high-risk" donor status does not significantly affect recipient outcome after heart transplantation in children. J Heart Lung Transplant. 2014;33(11):1173-1177.

28. Woolley AE, Singh SK, Goldberg HJ, et al. Heart and lung transplants from HCV-infected donors to uninfected recipients. N Engl J Med. 2019;380(17):1606-1617.

29. Godown J, Kirk R, Joong A, et al. Variability in donor selection among pediatric heart transplant providers: Results from an international survey. Pediatr transplant. 2019;23:e13417.

30. Huang S, Tang Y, Zhu Z, et al. Outcomes of organ transplantation from donors with a cancer history. Med Sci Monit. 2018;24:997-1007.

31. Fiaschetti P, Pretagostini R, Stabile D, et al. The use of neoplastic donors to increase the donor pool. Transplant Proc. 2012;44(7):1848-1850.

32. Nalesnik MA, Woodle ES, DiMaio JM, et al. Donor-transmitted malignancies in organ transplantation: assessment of clinical risk. Am J Transplant. 2011;11(6):1140-1147.

33. Plymale J, Park J, Natale J, Moon-Grady A. Corrected QT interval in children with brain death. Pediatr Cardiol. 2010;31(7):1064-1069.

34. Silva JNA, Canter CE, Singh TP, et al. Outcomes of heart transplantation using donor hearts from infants with sudden infant death syndrome. J Heart Lung Transplant. 2010;29(11):1226-1230.

35. Domico M, Checchia PA. Biomonitors of cardiac injury and performance: B-type natriuretic peptide and troponin as monitors of hemodynamics and oxygen transport balance. Pediatr Crit Care Med. 2011;12(4 Suppl):S33-S42.
36. Kutschmann M, Fischer-Fröhlich C-L, Schmidtmann I, et al. The joint impact of donor and recipient parameters on the outcome of heart transplantation in Germany after graft allocation. Transpl Int. 2013;27(2):152-161

37. Boccheciampe N, Audibert G, Rangeard O, et al. Serum troponin Ic values in organ donors are related to donor myocardial dysfunction but not to graft dysfunction or rejection in the recipients. Int $J$ Cardiol. 2009;133(1):80-86.

38. Madan S, Saeed O, Shin J, et al. Troponin and survival after cardiac transplantation: an analysis of the united network of organ sharing registry. Circ Heart Fail. 2016;9(6):e002909.

39. Madan S, Saeed O, Vlismas P, et al. Outcomes after transplantation of donor hearts with improving left ventricular systolic dysfunction. J Am Coll Cardiol. 2017;70(10):1248-1258.

40. Venkateswaran RV, Ganesh JS, Thekkudan J, et al. Donor cardiac troponin-I: a biochemical surrogate of heart function放访访. Eur J Cardiothorac Surg. 2009;36(2):286-292.

41. Khush KK, Menza RL, Babcock WD, Zaroff JG. Donor cardiac troponin I levels do not predict recipient survival after cardiac transplantation. J Heart Lung Transplant. 2007;26(10):1048-1053.

42. Szarszoi O, Besik J, Smetana M, et al. Biomarkers of cellular apoptosis and necrosis in donor myocardium are not predictive of primary graft dysfunction. Physiol Res. 2016;65(2):251-257.

43. Lin KY, Sullivan P, Salam A, et al. Troponin I levels from donors accepted for pediatric heart transplantation do not predict recipient graft survival. J Heart Lung Transplant. 2011;30(8):920-927.

44. Lieppman K, Kramer-Clark L, Tobias JD. Plasma B-type natriuretic peptide monitoring to evaluate cardiovascular function prior to organ procurement in patients with brain death. Paediatr Anaesth. 2008;18(9):852-856.

45. Dronavalli VB, Banner NR, Bonser RS. Assessment of the potential heart donor: a role for biomarkers? J Am Coll Cardiol. 2010;56(5):352-361

46. Amir NL, Gerber IL, Edmond JJ, Langlands JM, Richards AM, Ruygrok PN. Plasma B-type natriuretic peptide levels in cardiac donors. Clin Transplant. 2009;23(2):174-177.

47. Vorlat A, Conraads VM, Jorens PG, et al. Donor B-type natriuretic peptide predicts early cardiac performance after heart transplantation. J Heart Lung Transplant. 2012;31(6):579-584.

48. Ford MA, Almond CS, Gauvreau K, et al. Association of graft ischemic time with survival after heart transplant among children in the United States. J Heart Lung Transplant. 2011;30(11):1244-1249.

49. Russo MJ, Chen JM, Sorabella RA, et al. The effect of ischemic time on survival after heart transplantation varies by donor age: an analysis of the United Network for Organ Sharing database. J Thorac Cardiovasc Surg. 2007;133(2):554-559.

50. Conway J, Chin C, Kemna M, et al. Donors' characteristics and impact on outcomes in pediatric heart transplant recipients. Pediatr Transplant. 2013;17(8):774-781.

51. Rodrigues $\mathrm{W}$, Carr M, Ridout D, et al. Total donor ischemic time: Relationship to early hemodynamics and intensive care morbidity in pediatric cardiac transplant recipients*. Pediatr Crit Care Med. 2011;12(6):660-666.

52. Rossano JW, Cherikh WS, Chambers DC, et al. The Registry of the International Society for Heart and Lung Transplantation: Twentieth Pediatric Heart Transplantation Report-2017; Focus Theme: allograft ischemic time. J Heart Lung Transplant. 2017;36(10):1060-1069.

53. Vanderlaan RD, Manlhiot C, Conway J, Honjo O, McCrindle BW, Dipchand Al. Perioperative factors associated with in-hospital mortality or retransplantation in pediatric heart transplant recipients. $J$ Thorac Cardiovasc Surg. 2014;148(1):282-289.

54. Kirk R, Edwards LB, Aurora P. Registry of the International Society for Heart and Lung Transplantation: twelfth official pediatric heart transplantation report-2009. J Heart Lung Transplant. 2009;28(10):993-1006 
55. Dipchand AI, Naftel DC, Feingold B, et al. Outcomes of children with cardiomyopathy listed for transplant: a multi-institutional study. J Heart Lung Transplant. 2009;28(12):1312-1321.

56. Conway J, Manlhiot C, Kirk R, Edwards LB, McCrindle BW, Dipchand Al. Mortality and morbidity after retransplantation after primary heart transplant in childhood: an analysis from the registry of the International Society for Heart and Lung Transplantation. J Heart Lung Transplant. 2014;33(3):241-251.

57. Crawford TC, Magruder JT, Grimm JC, et al. The paradoxical relationship between donor distance and survival after heart transplantation. Ann Thorac Surg. 2017;103(5):1384-1391.

58. Banner NR, Thomas HL, Curnow E, Hussey JC, Rogers CA, Bonser RS. The importance of cold and warm cardiac ischemia for survival after heart transplantation. Transplantation. 2008;86(4):542-547.

59. Latchana N, Peck JR, Whitson B, Black SM. Preservation solutions for cardiac and pulmonary donor grafts: a review of the current literature. J Thorac Dis. 2014;6(8):1143-1149.

60. Ardehali A, Esmailian F, Deng M, et al. Ex-vivo perfusion of donor hearts for human heart transplantation (PROCEED II): a prospective, open-label, multicentre, randomised non-inferiority trial. Lancet. 2015;385(9987):2577-2584.

61. García Sáez D, Zych B, Sabashnikov A, et al. Evaluation of the organ care system in heart transplantation with an adverse donor/recipient profile. Ann Thorac Surg. 2014;98(6): 2099-2106. Discussion 2105-2106.

62. Orioles A, Morrison WE, Rossano JW, et al. An under-recognized benefit of cardiopulmonary resuscitation. Crit Care Med. 2013;41(12):2794-2799.

63. L'Ecuyer T, Sloan K, Tang L. Impact of donor cardiopulmonary resuscitation on pediatric heart transplant outcome. Pediatr Transplant. 2011;15(7):742-745.

64. West S, Soar J, Callaway CW. The viability of transplanting organs from donors who underwent cardiopulmonary resuscitation: a systematic review. Resuscitation. 2016;108:27-33.

65. Kamran S, Conti F, Pomey M-P, Baron G, Calmus Y, VidalTrecan G. Patients' preferences in transplantation from marginal donors: results of a discrete choice experiment. Transpl Int. 2017;30(6):589-602.

66. Quader MA, Wolfe LG, Kasirajan V. Heart transplantation outcomes from cardiac arrest-resuscitated donors. J Heart Lung Transplant. 2013;32(11):1090-1095.

67. Galeone A, Varnous S, Lebreton G, et al. Impact of cardiac arrest resuscitated donors on heart transplant recipients' outcome. J Thorac Cardiovasc Surg. 2017;153(3):622-630.

68. Morrison AK, Gowda C, Tumin D, et al. Pediatric marginal donor hearts: Trends in US national use, 2005-2014. Pediatr Transplant. 2018;22(5):e13216-e13216.

69. Rizwan R, Zafar F, Bryant R, et al. The number of refusals for donor organ quality does not impact heart transplant outcomes in children. Ann Thorac Surg. 2018;105(4):1223-1230.

70. Nixon JL, Kfoury AG, Brunisholz K, et al. Impact of high-dose inotropic donor support on early myocardial necrosis and outcomes in cardiac transplantation. Clin Transplant. 2012;26(2):322-327.

71. Richmond ME, Easterwood R, Singh RK, et al. Low-dose donor dopamine is associated with a decreased risk of right heart failure in pediatric heart transplant recipients. Transplantation. 2016;100(12):2729-2734.

72. Angleitner P, Kaider A, Gökler J, et al. High-dose catecholamine donor support and outcomes after heart transplantation. J Heart Lung Transplant. 2018;37(5):596-603.

73. Quintana-Quezada RA, Rajapreyar I, Postalian-Yrausquin A, et al. Clinical factors implicated in primary graft dysfunction after heart transplantation: a single-center experience. Transplant Proc. 2016;48(6):2168-2171.

74. Benck U, Hoeger S, Brinkkoetter PT, et al. Effects of donor pre-treatment with dopamine on survival after heart transplantation: a cohort study of heart transplant recipients nested in a randomized controlled multicenter trial. J Am Coll Cardiol. 2011;58(17):1768-1777.

75. Khush KK, Menza R, Nguyen J, Goldstein BA, Zaroff JG, Drew BJ. Electrocardiographic characteristics of potential organ donors and associations with cardiac allograft use. Circ Heart Fail. 2012;5(4):475-483.

76. Leong D, Aintablian T, Kittleson M, et al. Prolonged corrected QT interval in the donor heart: Is there a risk? Clin Transplant. 2017;31(7):e12996-e12996.

77. Kobashigawa J, Khush K, Colvin M, et al. Report from the American Society of transplantation conference on donor heart selection in adult cardiac transplantation in the United States. Am J Transplant. 2017;17(10):2559-2566.

78. Costanzo MR, Dipchand A, Starling R, et al. The International Society of Heart and Lung Transplantation Guidelines for the care of heart transplant recipients. J Heart Lung Transplant. 2010;29(8):914-956.

79. Wever Pinzon O, Stoddard G, Drakos SG, et al. Impact of donor left ventricular hypertrophy on survival after heart transplant. Am J Transplant. 2011;11(12):2755-2761.

80. Smits JM, De Pauw M, de Vries E, et al. Donor scoring system for heart transplantation and the impact on patient survival. J Heart Lung Transplant. 2012;31(4):387-397.

81. Chen CW, Sprys MH, Gaffey AC, et al. Low ejection fraction in donor hearts is not directly associated with increased recipient mortality. J Heart Lung Transplant. 2017;36(6):611-615.

82. Rossano JW, Lin KY, Paridon SM, et al. Pediatric heart transplantation from donors with depressed ventricular function: an analysis of the United Network of Organ Sharing Database. Circ Heart Fail. 2013;6(6):1223-1229.

83. Venkateswaran RV, Townend JN, Wilson IC, Mascaro JG, Bonser RS, Steeds RP. Echocardiography in the potential heart donor. Transplantation. 2010;89(7):894-901.

84. Kubak BM, Gregson AL, Pegues DA, et al. Use of hearts transplanted from donors with severe sepsis and infectious deaths. J Heart Lung Transplant. 2009;28(3):260-265.

85. Chen S, Tierney ESS, Khush KK, et al. Reliability of echocardiographic measurements of left ventricular systolic function in potential pediatric heart transplant donors. J Heart Lung Transplant. 2015;34(1):100-106.

86. Khush KK, Nguyen J, Goldstein BA, McGlothlin DP, Zaroff JG. Reliability of transthoracic echocardiogram interpretation in potential adult heart transplant donors. J Heart Lung Transplant. 2015;34(2):266-269.

How to cite this article: McCulloch MA, Zuckerman WA, Möller T, et al. Effects of donor cause of death, ischemia time, inotrope exposure, troponin values, cardiopulmonary resuscitation, electrocardiographic and echocardiographic data on recipient outcomes: A review of the literature. Pediatr

Transplant. 2020;24:e13676. https://doi.org/10.1111/ petr.13676 